University of Washington Tacoma

UW Tacoma Digital Commons

2019

\title{
Breaking the Exclusionary Boundary Between User Experience and Access
}

Sushil K. Oswal

University of Washington Tacoma, oswal@uw.edu

Zsuzsanna B. Palmer

Sherena Huntsman

Follow this and additional works at: https://digitalcommons.tacoma.uw.edu/ias_pub

\section{Recommended Citation}

Palmer, Z. B., Oswal, S. K., \& Huntsman, S. (2019). Breaking the Exclusionary Boundary Between User Experience and Access. Proceedings of the 37th ACM International Conference on the Design of Communication, 37:1-37:2. https://doi.org/10.1145/3328020.3353920

This Conference Proceeding is brought to you for free and open access by the School of Interdisciplinary Arts and Sciences at UW Tacoma Digital Commons. It has been accepted for inclusion in SIAS Faculty Publications by an authorized administrator of UW Tacoma Digital Commons. 


\section{Breaking the Exclusionary Boundary between User Experience and Access}

\author{
Zsuzsanna B. Palmer \\ Department of Writing \\ Grand Valley State University \\ Allendale, Michigan, USA \\ palmerzs@gvsu.edu
}

\author{
Sushil K. Oswal \\ Interdisciplinary School \\ University of Washington \\ Tacoma, Washington, USA \\ oswal@u.washington.edu
}

\author{
Sherena Huntsman \\ English Department \\ Boise State University \\ Boise, Idaho, USA \\ sherenahuntsman@boisestate.edu
}

\begin{abstract}
This paper expands the scope of designing for accessibility by proposing three design strategies that allow crosspollinations between accessible, user-centered design, cross-cultural design, and participatory design to break down the boundaries between the concepts of user experience and accessibility while involving all users in the UX research and design process.
\end{abstract}

\section{CCS CONCEPTS}

-Human-centered computing $\rightarrow$ Accessibility design and evaluation methods;

\section{KEYWORDS}

Accessible UX; accessible design; participatory design; crosscultural design

\section{ACM Reference format:}

Zsuzsanna B. Palmer, Sushil K. Oswal, Sherena Huntsman. 2019. Breaking the exclusionary boundary between user experience and access. In SIGDOC '19: The 37th ACM International Conference on the Design of Communication Proceedings, October 04-06, 2019, Portland, OR, USA, 2 pages. https://doi.org/10.1145/3328020.3353920

\section{INTRODUCTION}

Accessible design work has mostly been focused on website accessibility ranging from suggesting evaluation frameworks [1, 2] to proposing effective strategies that incorporate accessibility into the design process early on [3, 4]. However, discussions of accessible web and document design in practice often get restricted to retrospectively achieving compliance to standards [4]. We expand the scope of designing for accessibility by proposing three design strategies that allow crosspollinations

Permission to make digital or hard copies of part or all of this work for personal or classroom use is granted without fee provided that copies are not made or distributed for profit or commercial advantage and that copies bear this notice and the full citation on the first page. Copyrights for third-party components of this work must be honored. For all other uses, contact the Owner/Author. SIGDOC '19, October 4-6, 2019, Portland, OR, USA (c) 2019 Copyright is held by the owner/author(s). ACM ISBN 978-1-4503-6790-5/19/10.

https://doi.org/10.1145/3328020.3353920 between accessible, user-centered design, cross-cultural design, and participatory design [5]. This multi-pronged approach will result in breaking down the boundaries between designers and users and between the concepts of user experience and accessibility.

\section{BRIDGING THE GAP BETWEEN DESIGNS AND BODIES}

The functional model of design places disability within a gap between the functional demands of an environment and the functional abilities of a user's body. Although this gap is readily witnessed in physical environments, such as the gap created when a design demands a user walk upstairs to access a building, this gap is also present in the way we design communication. We believe that the barriers to document accessibility exist within this gap between the functional demands of a document and the functional abilities of users' bodies [6]. For example, the functional demands of a document may include the ability to visibly see the document when not all users' functional abilities include physical sight. Because accessibility is a product of design and not an innate lack of ability in the user's body, accessibility can be addressed through our communication practices. The barrier to access is within the features of the document design.

To break down these barriers, we describe how we teach undergraduates to consider their users' bodies. We teach our students to use the functional model to anticipate the way users across the ability spectrum will access information through the products they design. We achieve this awareness by being transparent about our practices as we model accessible design strategies (e.g. headings, alt text) in our course documents. We then prioritize the same strategies in student assignments and class exercises, and in assessing students' abilities to implement these accessibility strategies throughout their communication projects.

\section{BUILDING ACCESS THROUGH CROSS- CULTURAL UX APPROACH}

Cross-cultural UX research, defined here as researching the user experience of similar websites in different countries, can greatly inform accessible design. This is especially the case when the UX researcher is not immersed in the national culture of the organization that applies her advice for ensuring the best possible user experience for all users of their website. To ensure that this 
type of research remains free from the researcher's cultural bias, it is even more important to allow for participatory processes when envisioning a more usable and accessible interface.

While participatory research/design should be included throughout the whole design process for accessible websites, we propose that it is an especially useful approach when creating and phrasing UX web-surveys [7]. Administering UX-web surveys is not only a quick and efficient way for researchers to collect a large amount of data remotely, but it can also provide an avenue for respondent participation in constructing what Cabrero calls UserCreated Personas [8]. As User-Created Personas are especially well-suited for avoiding cultural generalizations about the user based on the researcher's assumptions [9], they provide a tangible way to incorporate input from users into the process of designing digital interfaces across cultures. We suggest combining websurveys and User-Created Personas for UX research as this approach not only allows for data gathering remotely but can provide early input for usability and accessibility researchers as they work on improving websites.

\section{MAKING UX INCLUSIVE OF DISABLED USERS}

The accessibility needs of disabled users still remain cordoned off in UX design process [10]. Accessibility is retrofitted on UX designs conceptualized for nondisabled users. We propose that the user experience concept itself needs revising so that the artificial boundary between abled and disabled is taken down. Through users of diverse abilities participatorily defining the parameters and nature of user experience, we can teach this transgressive approach to design. Realizing this goal would require a primary attitudinal shift where we acknowledge that 1) our understanding of disabled users' experience is narrow and two dimensional; 2) disabled people are diverse individuals who are fully capable of describing their peculiar user needs; 3) disabled people in each disability group situate themselves differently in space and time to accommodate their physical and mental differences and varied contexts of use; 4) disabled users are possessors of privileged knowledge about their bodies and the peculiar strategies they adopt to maximize the outcome of their efforts when interacting with and within information, communication, and technology environments; and 5) they can become excellent ideational partners in design and development activity because their understanding of accessible technologies, spaces, and communications embody the experience of difference.

When the evolution of UX is seen through the lens of disability studies, user experience and participatory design do not appear as two isolated sets of practices. Techniques for fusing the concept of diverse abilities through participatory design with disabled users is a step toward extracting ourselves from the ableist aspects of UX practice and breaking the boundary between designers and disabled users through specific accessible design practices emerging out of these embodied experiences.

\section{REFERENCES}

[1] André P. Freire, Renata PM Fortes, Marcelo AS Turine, Debora Paiva. An evaluation of web accessibility metrics based on their attributes. Proceedings of the 26th annual ACM International Conference on Design of Communication (2008), 73-80. ACM.

[2] André De Lima Salgado, Sandra Souza Rodrigues, Renata Pontin M. Fortes. Evolving Heuristic Evaluation for multiple contexts and audiences: Perspectives from a mapping study. Proceedings of the 34th ACM International Conference on the Design of Communication, 19 (2016). ACM.

[3] Matthew J. Bell, and Colin HC Machin. A framework for adaptive communication design. Proceedings of the 27th ACM International Conference on Design of Communication (2009), 45-50. ACM.

[4] Willian Massami Watanabe, David Fernandes Neto, Thiago Jabur Bittar, and Renata PM Fortes. WCAG conformance approach based on model-driven development and WebML. Proceedings of the 28th ACM International Conference on Design of Communication (2010), 167-174. ACM.

[5] Sushil K Oswal. Participatory design: Barriers and possibilities. Communication Design Quarterly Review 2,3 (2014) 14-19.

[6] Annika Konrad. Reimagining work: Normative commonplaces and the effects on accessibility in workplaces. Business and Professional Communication Quarterly 18, 1 (2018), 123-141.

[7] Tanja Walsh, and Piia Nurkka. Approaches to cross-cultural design: two case studies with UX web-surveys. Proceedings of the 24th Australian ComputerHuman Interaction Conference (2012), 633-642. ACM.

[8] Daniel G. Cabrero. User-created persona: Namibian rural Otjiherero speakers. In Proceedings of the 33rd Annual International Conference on the Design of Communication (2015). ACM.

[9] Daniel G. Cabrero, Heike Winschiers-Theophilus, Jose Abdelnour-Nocera, and Gereon Koch Kapuire. A hermeneutic inquiry into user-created personas in different Namibian locales. Proceedings of the 14th Participatory Design Conference: Full papers-Volume 1 (2016), 101-110. ACM.

[10] Chandrashekar Sambhavi, Rachel Benedyk. Accessibility vs. usability: Where is the dividing line contemporary ergonomics. Proceedings of the Ergonomics Society's Annual Conference (2006). 